\title{
Haemostatic drugs for traumatic brain injury (Review)
}

\author{
Perel P, Roberts I, Shakur H, Thinkhamrop B, Phuenpathom N, Yutthakasemsunt S
}

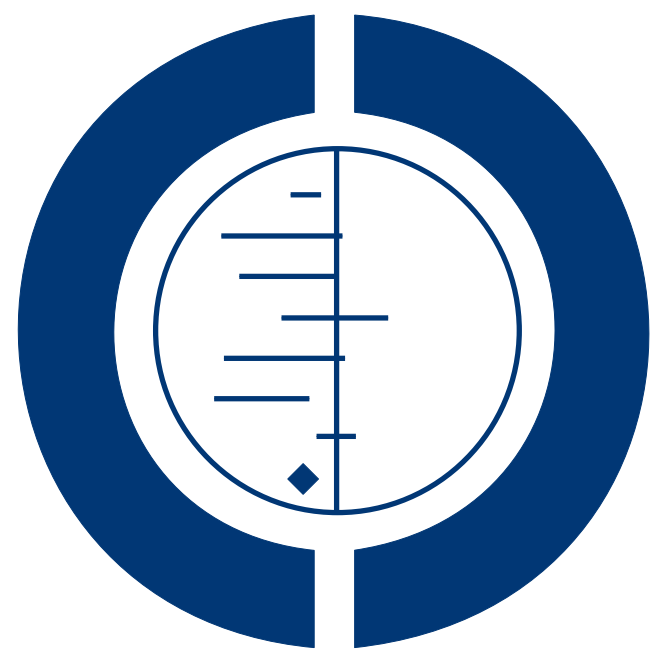

\section{THE COCHRANE COLLABORATION $^{\circledR}$}

This is a reprint of a Cochrane review, prepared and maintained by The Cochrane Collaboration and published in The Cochrane Library 2010, Issue 1

http://www.thecochranelibrary.com

\section{WILEY}

Haemostatic drugs for traumatic brain injury (Review)

Copyright @ 2010 The Cochrane Collaboration. Published by John Wiley \& Sons, Ltd. 
TABLE OF CONTENTS

HEADER . . . . . . . . . . . . . . . . . . . . . . . . . . . . . . . . . . . . . . . 1

ABSTRACT . . . . . . . . . . . . . . . . . . . . . . . . . . . . . . . . . . . . . . . . . . . .

PLAIN LANGUAGE SUMMARY . . . . . . . . . . . . . . . . . . . . . . . . . . . . . . . . . . . 2

BACKGROUND . . . . . . . . . . . . . . . . . . . . . . . . . . . . . . . . . . . . . .

OBJECTIVES . . . . . . . . . . . . . . . . . . . . . . . . . . . . . . . . . . . . . .

METHODS . . . . . . . . . . . . . . . . . . . . . . . . . . . . . . . . . . . . . .

RESULTS . . . . . . . . . . . . . . . . . . . . . . . . . . . . . . . . . . . . . 5

Figure 1. . . . . . . . . . . . . . . . . . . . . . . . . . . . . . . . . . . 6

Figure 2. . . . . . . . . . . . . . . . . . . . . . . . . . . . . . . . . . . . . . . . . . . 7

DISCUSSION . . . . . . . . . . . . . . . . . . . . . . . . . . . . . . . . . . . . . . . . . . . . . . . .

AUTHORS' CONCLUSIONS . . . . . . . . . . . . . . . . . . . . . . . . . . . . . . . . . . . . .

REFERENCES . . . . . . . . . . . . . . . . . . . . . . . . . . . . . . . . . . . . . . 9

CHARACTERISTICS OF STUDIES . . . . . . . . . . . . . . . . . . . . . . . . . . . . . . . . . . . . . .

DATA AND ANALYSES . . . . . . . . . . . . . . . . . . . . . . . . . . . . . . . . . . . . . . . . . 15

Analysis 1.1. Comparison 1 Outcomes, Outcome 1 Mortality. . . . . . . . . . . . . . . . . . . . 15

Analysis 1.2. Comparison 1 Outcomes, Outcome 2 Thrombotic complication. . . . . . . . . . . . . . . . 16

Analysis 1.3. Comparison 1 Outcomes, Outcome 3 Change in volume of intracranial bleeding. . . . . . . . . . 16

APPENDICES . . . . . . . . . . . . . . . . . . . . . . . . . . . . . . . . . . . . . 16

HISTORY . . . . . . . . . . . . . . . . . . . . . . . . . . . . . . . . . . . . . . . 22

CONTRIBUTIONS OF AUTHORS . . . . . . . . . . . . . . . . . . . . . . . . . . . . . . . . . . . . . .

DECLARATIONS OF INTEREST . . . . . . . . . . . . . . . . . . . . . . . . . . . . . . . . 22

SOURCES OF SUPPORT . . . . . . . . . . . . . . . . . . . . . . . . . . . . . . . . . . . . . 23

DIFFERENCES BETWEEN PROTOCOL AND REVIEW . . . . . . . . . . . . . . . . . . . . . . . . 23

INDEX TERMS . . . . . . . . . . . . . . . . . . . . . . . . . . . . . . . . . . . . . 23

Haemostatic drugs for traumatic brain injury (Review)

Copyright $\odot 2010$ The Cochrane Collaboration. Published by John Wiley \& Sons, Ltd. 


\section{[Intervention Review]}

\section{Haemostatic drugs for traumatic brain injury}

Pablo Perel $^{1}$, Ian Roberts ${ }^{1}$, Haleema Shakur ${ }^{1}$, Bandit Thinkhamrop ${ }^{2}$, Nakornchai Phuenpathom ${ }^{3}$, Surakrant Yutthakasemsunt ${ }^{4}$

${ }^{1}$ Cochrane Injuries Group, London School of Hygiene \& Tropical Medicine, London, UK. ${ }^{2}$ Department of Demography and Biostatistics, Khon Kaen University, Khon Kaen, Thailand. ${ }^{3}$ Division of Neurosurgery, Department of Surgery, Faculty of Medicine, Prince of Songkla University, Hadyai, Songkla, Thailand. ${ }^{4}$ Khon Kaen Regional Hospital, Khon Kaen, Thailand

Contact address: Pablo Perel, Cochrane Injuries Group, London School of Hygiene \& Tropical Medicine, Keppel Street, London, WC1E 7HT, UK. pablo.perel@Lshtm.ac.uk.

Editorial group: Cochrane Injuries Group.

Publication status and date: New, published in Issue 1, 2010.

Review content assessed as up-to-date: 2 February 2009.

Citation: Perel P, Roberts I, Shakur H, Thinkhamrop B, Phuenpathom N, Yutthakasemsunt S. Haemostatic drugs for traumatic brain injury. Cochrane Database of Systematic Reviews 2010, Issue 1. Art. No.: CD007877. DOI: 10.1002/14651858.CD007877.pub2.

Copyright (C) 2010 The Cochrane Collaboration. Published by John Wiley \& Sons, Ltd.

A B S T R A C T

\section{Background}

Traumatic brain injury (TBI) is a leading cause of death and disability. Intracranial bleeding is a common complication of TBI, and intracranial bleeding can develop or worsen after hospital admission. Haemostatic drugs may reduce the occurrence or size of intracranial bleeds and consequently lower the morbidity and mortality associated with TBI.

\section{Objectives}

To assess the effects of haemostatic drugs on mortality, disability and thrombotic complications in patients with traumatic brain injury.

\section{Search methods}

We searched the electronic databases: Cochrane Injuries Group Specialised Register (3 February 2009), CENTRAL (The Cochrane Library 2009, Issue 1), MEDLINE (1950 to Week 3 2009), PubMed (searched 3 February 2009 (last 180 days)), EMBASE (1980 to Week 4 2009), CINAHL (1982 to January 2009), ISI Web of Science: Science Citation Index Expanded (SCI-EXPANDED) (1970 to January 2009), ISI Web of Science: Conference Proceedings Citation Index - Science (CPCI-S) (1990 to January 2009).

\section{Selection criteria}

We included published and unpublished randomised controlled trials comparing haemostatic drugs (antifibrinolytics: aprotinin, tranexamic acid (TXA), aminocaproic acid or recombined activated factor VIIa (rFVIIa)) with placebo, no treatment, or other treatment in patients with acute traumatic brain injury.

\section{Data collection and analysis}

Two review authors independently examined all electronic records, and extracted the data. We judged that there was clinical heterogeneity between trials so we did not attempt to pool the results of the included trials. The results are reported separately.

\section{Main results}

We included two trials. One was a post-hoc analysis of 30 TBI patients from a randomised controlled trial of rFVIIa in blunt trauma patients. The risk ratio for mortality at 30 days was 0.64 (95\% CI 0.25 to 1.63 ) for rFVIIa compared to placebo. This result should be considered with caution as the subgroup analysis was not pre-specified for the trial. The other trial evaluated the effect of $\mathrm{rFVIIa}$ in 97 TBI patients with evidence of intracerebral bleeding in a computed tomography (CT) scan. The corresponding risk ratio for mortality

Haemostatic drugs for traumatic brain injury (Review)

Copyright $\odot 2010$ The Cochrane Collaboration. Published by John Wiley \& Sons, Ltd. 
at the last follow up was 1.08 (95\% CI 0.44 to 2.68). The quality of the reporting of both trials was poor so it was difficult to assess the risk of bias.

\section{Authors' conclusions}

There is no reliable evidence from randomised controlled trials to support the effectiveness of haemostatic drugs in reducing mortality or disability in patients with TBI. New randomised controlled trials assessing the effects of haemostatic drugs in TBI patients should be conducted. These trials should be large enough to detect clinically plausible treatment effects.

\section{PLAIN LANGUAGE SUMMARY}

\section{Haemostatic drugs for traumatic brain injury}

Injury (also called trauma) is a leading cause of death for children and young adults. Traumatic brain injury, such as from a blow to the head, is a frequent cause of death for patients with trauma who survive to reach hospital. Approximately half of patients with traumatic brain injury develop bleeding into the brain within the first 48 hours of hospital admission. If bleeding occurs, accumulating blood within the skull can put pressure on the brain and this may be fatal or result in serious long-term disability for the patient. Therefore, drugs that promote the production of clots or reduce the destruction of existing clots (known as haemostatic drugs) might reduce the bleeding into the brain after an injury and thereby reduce the risk of death or disability.

We searched for randomised clinical trials looking at the effectiveness of haemostatic drugs for reducing mortality and disability in patients with traumatic brain injury. We found two studies that evaluated the effects of a type of haemostatic drug called recombined activated factor VII. We reviewed the data presented in the reports of these trials. Both trials were too small to confirm or refute any plausible clinical effect, so we were unable to reach any conclusions regarding the effectiveness of haemostatic drugs for traumatic brain injury patients. More trials are needed to answer this question. Future trials should be large enough to detect plausible and important clinical effects.

\section{B A C K G RO U N D}

\section{Description of the condition}

Traumatic brain injury is one of the main causes of death in patients with injuries, and is a leading cause of death and disability in young people (Ghajar 2000). Every year approximately 1.5 million people die and at least 10 million people are killed or hospitalised because of a traumatic brain injury (Langlois 2006). The incidence, fatality and disability rates are higher in low- and middle- income countries than in high income countries (Hyder 2007).

Although much of the damage to the brain occurs at the time of the injury, secondary brain damage due to ongoing intracranial bleeding and brain swelling is an important and potentially avoidable cause of morbidity and mortality. Intracranial bleeding is a common complication of traumatic brain injury. In the CRASH trial, which included patients with mild, moderate and severe traumatic brain injury, $56 \%$ of trial participants had at least one intracranial bleed that could have been epidural, subdural, subarachnoid or intra-parenchymal (CRASH Trial).

There is evidence that intracranial bleeding can develop or worsen after hospital admission. Prospective observational studies have shown that traumatic intracranial haemorrhage expansion occurs in up to $51 \%$ of patients with traumatic brain injury during the first 24 to 48 hours after hospital admission (Narayan 2008). Prognostic studies have shown that intracranial haemorrhage is associated with increased mortality and disability six months after injury (Maas 2007; Perel 2008). Intracranial bleeding exerts significant pressure on brain tissue (Bullock 2006), and prompt neurosurgical intervention is an important part of the therapeutic approach. However, not all intracranial haemorrhages can be controlled by surgical intervention and there is interest in pharmacological approaches that use haemostatic drugs to reduce the occurrence or size of intracranial bleeds (Ceylan 1992; Mandera 1999; Holcomb 2004).

Haemostatic drugs for traumatic brain injury (Review)

Copyright $\Subset 2010$ The Cochrane Collaboration. Published by John Wiley \& Sons, Ltd. 


\section{Description of the intervention}

Haemostatic drugs have the potential to reduce bleeding by influencing the coagulation cascade. In the haemostatic process, coagulation occurs rapidly to build a tight net of fibrin at the site of the damaged vessel. At the same time, the fibrinolytic system removes fibrin deposits that could cause permanent occlusion of blood vessels once vascular repair has taken place (Prentice 1980). Thus, the coagulation and fibrinolytic systems are in a state of dynamic balance that maintains an intact vascular system.

The treatments that have been most extensively evaluated as haemostatic drugs include antifibrinolytics and pro-coagulant drugs such as recombinant activated factor VII (rFVIIa) ( Mannucci 2007). Antifibrinolytic drugs maintain the stability of blood clots, whereas pro-coagulant drugs act directly on the coagulation cascade (Holcomb 2004).

The pro-coagulant rFVIIa acts locally at the site of tissue injury. It is believed that it binds to exposed tissue factor and generates thrombin, which activates the platelets. The activated platelet surface forms a template on which recombinant factor VIIa can directly or indirectly mediate further activation of coagulation, resulting in the generation of more thrombin and, ultimately, in the conversion of fibrinogen to fibrin.

Antifibrinolytic agents suppress fibrinolysis, thereby reducing excessive or recurrent bleeding. Antifibrinolytics can be divided into lysine analogues (tranexamic acid (TXA) and aminocaproic acid) and plasmin inhibitors (aprotinin). The former impairs endogenous fibrinolysis by blocking lysine binding sites on plasminogen molecules. In contrast, aprotinin directly inhibits the fibrinolytic enzyme plasmin, plasma and tissue kallikrein, trypsin and activated coagulation factor XII.

\section{How the intervention might work}

Haemostatic drugs have been used to prevent or reduce blood loss and the need for blood transfusion.

For example, antifibrinolytic drugs are widely used in general surgery to reduce bleeding and the need for transfusions (Slaughter 1997). A systematic review of the use of antifibrinolytic agents in surgical patients identified 211 randomised controlled trials that included 20,781 participants (Henry 2007). The results showed that TXA reduced the risk of blood transfusion by $39 \%$ (risk ratio (RR) $0.61,95 \%$ confidence interval (CI) 0.54 to 0.69 ), while aprotinin lowered the risk by $34 \%$ (RR $0.66,95 \%$ CI 0.61 to 0.71 ). Antifibrinolytic agents also reduced the need for blood transfusion and reoperation due to bleeding. There was a trend toward a decreased risk of death in patients treated with aprotinin (RR 0.90 , 95\% CI 0.67 to 1.20 ) and TXA (RR $0.60,95 \%$ CI 0.32 to 1.12 ) but this was not statistically significant. There was no evidence of an increased risk of thrombotic events with either treatment.

The effects of haemostatic drugs in non-traumatic intracranial bleeding have also been evaluated. A systematic review of ran- domised controlled trials of antifibrinolytic drugs in patients with aneurysmal subarachnoid haemorrhage showed that antifibrinolytic drugs reduced the rate of re-bleeding by approximately $40 \%$ but, because of the associated increase in cerebral ischaemia, there was no overall benefit (Roos 2003). However, the length of treatment in these trials was six weeks. It is possible that a shorter treatment period might prevent re-bleeding without increasing the risk of ischaemia. The systematic review was conducted in 2003. Since then, a randomised controlled trial of early administration of a short course (three days) of TXA in patients with aneurysmal subarachnoid haemorrhage has found that TXA reduced the occurrence of re-bleeding from $10.8 \%$ to $2.4 \%$, with no evidence of increased side effects (Astrup 2006).

A systematic review of haemostatic drugs in primary intracerebral haemorrhage (non-traumatic) found four phase II trials and reported that haemostatic drugs reduced the risk of death and dependence measured on the modified Rankin Scale (RR 0.79, 95\% CI 0.67 to 0.93 ) and the Glasgow Outcome Scale (RR 0.90, 95\% CI 0.81 to 1.01) (You 2006). A recent clinical trial, which was not included in that systematic review, showed that activated factor VIIa reduced intracerebral haemorrhage expansion but did not improve the survival or functional outcomes of patients (Mayer 2008).

\section{Why it is important to do this review}

If haemostatic agents reduce intracranial bleeding in patients with traumatic brain injury, they could substantially reduce the extent of secondary brain damage and subsequently lower the mortality and morbidity rates associated with brain injury. Given the number of cases of traumatic brain injury that occur each year, even a modest reduction in the risk of unfavourable outcomes could have major public health implications.

\section{O B JE C T IVES}

To assess the effects of haemostatic drugs on mortality, disability and thrombotic complications in patients with traumatic brain injury.

\section{METHODS}

\section{Criteria for considering studies for this review}


We included published and unpublished randomised controlled trials comparing haemostatic drugs with placebo, no treatment, or other treatment in patients with acute traumatic brain injury. Comparisons between different types of haemostatic drugs were also to be included.

\section{Types of participants}

Any patient with traumatic brain injury.

\section{Types of interventions}

Any of the systemic haemostatic drugs listed below compared with placebo, no treatment, or another haemostatic drug. For studies in which different doses of the intervention were compared with placebo, the intervention groups were combined and compared with the control group. For the purpose of this review, we considered the following haemostatic drugs.

- Antifibrinolytics: aprotinin, tranexamic acid (TXA), aminocaproic acid.

- Activated factor VIIa.

\section{Types of outcome measures}

\section{Primary outcomes}

1. Mortality

2. Disability (Glasgow Outcome Scale (GOS), Disability Rating Scale (DRS), or other measure of neurological function)

3. Thrombotic complications: deep venous thrombosis (DVT), pulmonary embolism (PE), stroke, and myocardial infarction (MI)

\section{Secondary outcomes}

1. Volume of intracranial bleeding

2. Brain ischaemic lesions

3. Need for neurosurgical operation or reoperation

4. Renal failure

\section{Search methods for identification of studies}

The searches were not restricted by date, language, or publication status.

\section{Electronic searches}

We searched the following electronic databases:

- Cochrane Injuries Group Specialised Register (searched 3

February 2009),

- CENTRAL (The Cochrane Library 2009, Issue 1),
- MEDLINE (1950 to Week 3 2009),

- PubMed (searched 3 February 2009 (last 180 days)),

- EMBASE (1980 to Week 4 2009),

- CINAHL (1982 to January 2009),

- ISI Web of Science: Science Citation Index Expanded (SCIEXPANDED) (1970 to January 2009),

- ISI Web of Science: Conference Proceedings Citation Index - Science (CPCI-S) (1990 to January 2009).

The full search strategies can be found in Appendix 1 .

\section{Searching other resources}

We searched the Internet for relevant information and conference abstracts. We also sought other potentially relevant published, unpublished, or ongoing studies by:

1. checking the reference lists of relevant papers and literature reviews,

2. communicating with relevant trial authors,

3. contacting the manufacturers of relevant drugs.

\section{Data collection and analysis}

\section{Selection of studies}

Two review authors (PP and IR) independently examined all electronic records and their abstracts to establish eligibility. They decided on whether or not to acquire the full report and, in cases of uncertainty, obtained the full report. We planned to resolve any disagreements through discussion and consultation with a third review author. Any duplicate trials were planned to be examined individually to verify that they presented unique sets of data. If we were unsure about whether a study should be included, because additional information was necessary, we allocated the study to the list of those awaiting assessment and contacted the study authors for clarification. The reasons for excluding studies are described in the 'Characteristics of excluded studies' table.

\section{Data extraction and management}

Two review authors (PP and IR) extracted the data from the included studies. We extracted data on the study methods, participants, interventions, and outcomes. We extracted data so that an intention-to-treat analysis could be performed. For binary outcomes, we determined the number of participants experiencing the outcome of interest in each group. For continuous outcomes, we used the mean change from baseline at final assessment, together with the number of participants and standard deviation for each group. 


\section{Assessment of risk of bias in included studies}

Two review authors (PP and IR) evaluated the risk of bias of the included studies with respect to six domains: sequence generation, allocation concealment, blinding, incomplete outcome data, selective outcome reporting, and other sources of bias. The risk of bias in each domain was rated as high risk, low risk, and unclear. Any disagreement between raters was resolved by consensus.

\section{Measures of treatment effect}

For dichotomous data, we calculated the risk ratio (RR) and 95\% CI. We calculated the mean difference (MD) and 95\% CI for continuous outcomes that were measured on the same scale, otherwise we planned to calculate the standardised mean difference.

\section{Dealing with missing data}

We attempted to contact study authors to obtain any missing information.

\section{Assessment of heterogeneity}

We planned to examine the participants, interventions, and outcomes of the trials for evidence of clinical heterogeneity. Statistical heterogeneity was planned to be examined with the $\mathrm{I}^{2}$ statistic and $\mathrm{Chi}^{2}$ test. The $\mathrm{I}^{2}$ statistic describes the percentage of total variation across studies that is due to heterogeneity rather than chance. A value of $0 \%$ indicates no observed heterogeneity; larger values show increasing heterogeneity. Substantial heterogeneity is considered to exist when $\mathrm{I}^{2}$ is more than $50 \%$. For the Chi ${ }^{2}$ test, a $\mathrm{P}$ value of less than 0.10 was considered as indicating the presence of statistically significant heterogeneity. We planned that if there was any evidence of clinical or statistical heterogeneity, we would not conduct a meta-analysis and would report findings in a narrative form.

\section{Assessment of reporting biases}

We planned to assess reporting bias using a funnel plot.

\section{Data synthesis}

We planned to conduct a meta-analysis if the included trials were clinically homogeneous and there was no evidence of statistical heterogeneity. For dichotomous outcomes, we planned to use the Mantel-Haenszel method.

\section{Subgroup analysis and investigation of heterogeneity}

If significant heterogeneity was present, and the number of studies was sufficient, we planned to investigate heterogeneity using the following subgroups.
1. Severity of acute traumatic brain injury (mild, moderate, or severe).

2. Type of traumatic brain injury lesion (focal or diffuse).

3. Type of intervention (i.e. kind of haemostatic drug used).

\section{Sensitivity analysis}

We planned to perform a sensitivity analysis to investigate the effect of the methodological quality of the included studies on the results.

\section{RES U L T S}

\section{Description of studies}

See: Characteristics of included studies; Characteristics of excluded studies; Characteristics of studies awaiting classification; Characteristics of ongoing studies.

\section{Results of the search}

The search of the databases identified a total of 659 records. These were screened by two authors (PP and IR) and the full text of 12 potentially eligible reports were obtained for closer examination. Of these, only two studies met the inclusion criteria. A further study was identified by searching the reference lists of selected seminal papers.

\section{Included studies}

Two trials were included in this systematic review. Both evaluated the effects of recombinant factor VIIa (rFVIIa). The earlier of these trials (Kluger 2007) was a post-hoc analysis of traumatic brain injury (TBI) patients from a randomised controlled trial of rFVIIa in blunt trauma patients (Boffard 2005). The later paper evaluated the effects of rFVIIa in TBI patients with evidence of intracerebral bleeding of at least $2 \mathrm{ml}$ on a baseline computed tomography (CT) scan obtained within six hours of the injury (Narayan 2008). More details about the studies are reported in the 'Characteristics of included studies' table.

\section{Excluded studies}

We identified a trial that evaluated the effects of aprotinin in patients with severe TBI (Auer 1979). It was reported as a randomised controlled trial; however after randomly allocating the first $20 \mathrm{pa}-$ tients, five patients were added to the aprotinin group. It was not possible to separate the outcome data for the 20 randomised and the five non-randomised patients. Therefore, this study provided no useable outcome data and was excluded. 
Pending study results

Another trial that could contribute useful data to this systematic review was a phase 3 randomised controlled trial that evaluated the effect of rFVIIa in trauma patients. This trial planned to recruit 1502 patients but it was stopped by its sponsor after 550 patients because of futility (Novoseven Study). Although we contacted the sponsor of this trial, as of July 2009 we were not able to obtain any data.

\section{Ongoing studies}

There are three ongoing trials that could contribute to this systematic review. The CRASH-2 trial (CRASH-2 Trial) is an international study evaluating the effects of TXA in patients with trauma and significant bleeding; a subgroup analysis of TBI patients is planned. CRASH-2 aims to recruit 20,000 patients and will be finished by December 2009. An explanatory study, CRASH-2 IBS (Intracranial Bleeding Study) is also being conducted among a sample of $300 \mathrm{CRASH}-2$ participants. In patients recruited to CRASH-2 IBS, a second CT scan is obtained within 24-48 hours after randomisation to evaluate changes in the volume of intracranial bleeding. Another trial is being conducted in Thailand to evaluate the effectiveness and safety of TXA for adult patients with moderate to severe TBI. It was to recruit 240 patients and should have been finished by May 2009 (Tranexamic acid in TBI).

\section{Risk of bias in included studies}

The review authors' assessment of the risk of bias for each included study can be found in Figure 1 and Figure 2.

Figure I. Methodological quality summary: review authors' judgements about each methodological quality item for each included study.

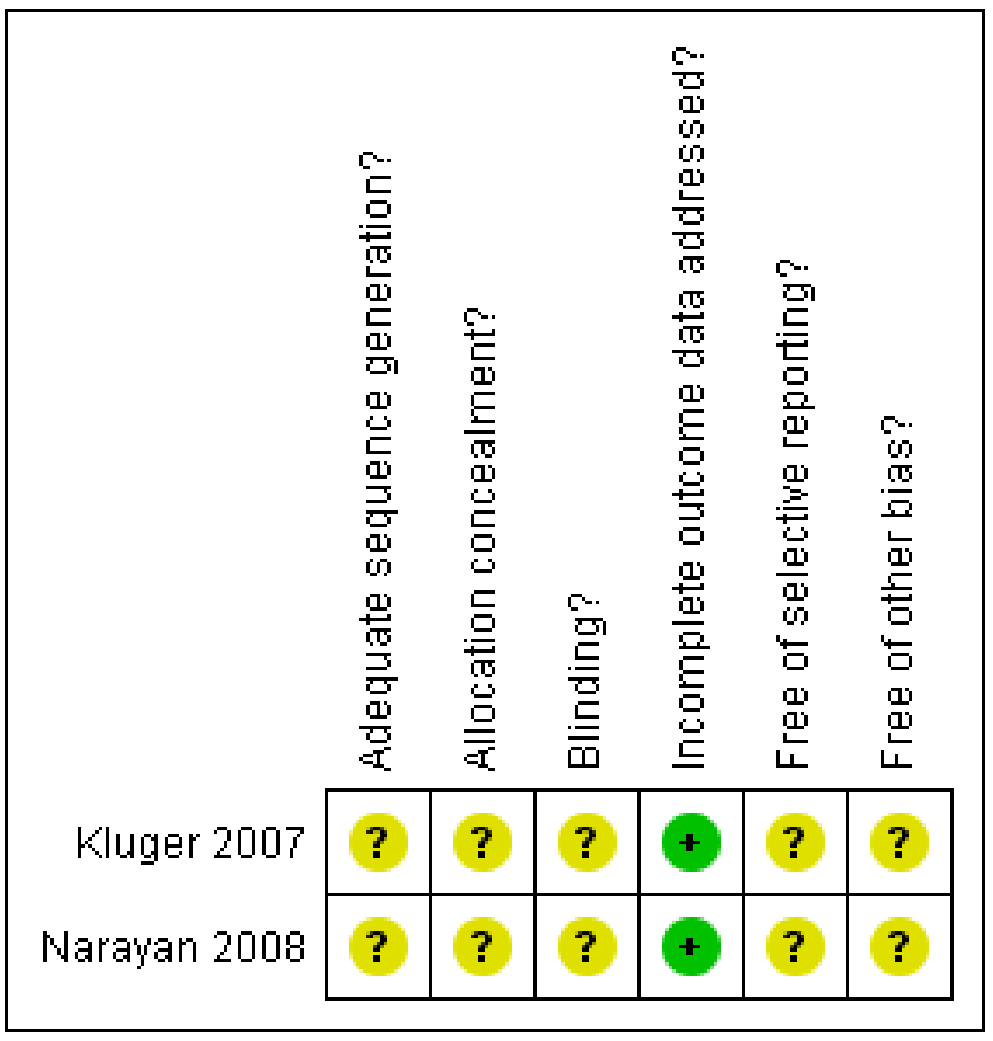

Haemostatic drugs for traumatic brain injury (Review)

Copyright @ 2010 The Cochrane Collaboration. Published by John Wiley \& Sons, Ltd. 
Figure 2. Methodological quality graph: review authors' judgements about each methodological quality item presented as percentages across all included studies. Two studies are included in this review.

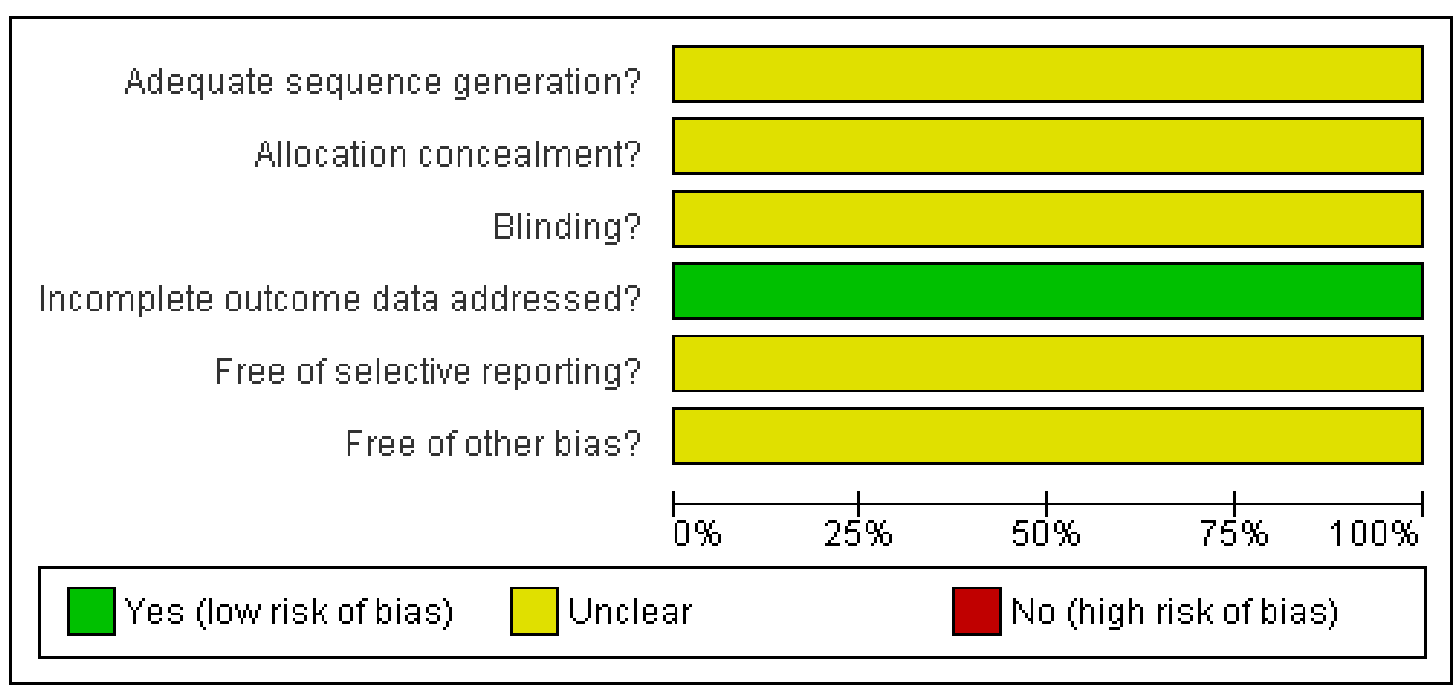

\section{Allocation}

Method of allocation concealment was not reported in either of the included studies.

\section{Blinding}

Although both studies were reported to be 'double blind' they did not describe the method of blinding.

\section{Incomplete outcome data}

Both studies reported the pre-specified outcomes for all included patients. However, in the trial by Narayan and collaborators only mortality at 15 days was reported. They also reported in-hospital mortality after 15 days but it was not clear if this information was collected for all the patients.

\section{Selective reporting}

A protocol was not available for either of the included studies, so it was not possible to assess the presence of reporting bias.

\section{Effects of interventions}

We did not attempt to combine the results of the two included trials as we judged that they included two different populations. One study evaluated the effect of rFVIIa in trauma patients with extracranial bleeding who also had a TBI (Kluger 2007), and the other study only included patients with mild and moderate TBI and evidence of traumatic intracranial bleeding in the CT scan (Narayan 2008).

\section{Primary outcomes \\ Mortality}

Both studies reported on mortality.

Kluger 2007 reported a RR for mortality at 30 days of 0.64 (95\% CI 0.25 to 1.63 ) for patients receiving rFVIIa in comparison to those receiving placebo.

Narayan 2008 reported a RR for mortality at the last follow-up time of 1.08 (95\% CI 0.44 to 2.68 ) for patients receiving rFVIIa in comparison to those receiving placebo.

\section{Disability}

Kluger 2007 did not report the effect of rFVIIa on disability.

Narayan 2008 evaluated the effect on disability using the GOS and the Barthex Index (BI).

The BI was evaluated in only $71(76 \%)$ patients. The authors reported that the median scores were 46.3 and 43.9 for the placebo and rFVIIa arms, respectively. However, their report did not provide enough data (SD and denominators) to estimate the mean difference between the two groups. Similarly, insufficient data were reported to evaluate the effect on GOS. It was reported that at 15 days, $17 \%$ of the patients in the placebo and $18 \%$ in the rFVIIa group had moderate to good recovery according to the GOS.

\section{Thrombotic complications}

Both studies reported the effect of rFVIIa on thrombotic complications.

Kluger 2007 followed the 'local diagnostic procedures' in the case of clinical symptoms of thromboembolic events. They reported two serious adverse thromboembolic events in the placebo arm 
and none in the rFVIIa arm (RR 0.16, 95\% CI 0.01 to 2.99 for rFVIIa in comparison to placebo).

Narayan 2008 conducted a more intense follow up of patients to detect thromboembolic complications. An ultrasound screening of the lower extremities (USLE) was mandated by protocol at 72 \pm 8 hours to detect the presence of DVT. A 12-lead electrocardiogram (ECG) and a centralised laboratory measurement of troponin I were mandated at baseline and 24 hours after trial drug administration. The authors reported that eight patients (13\%) from the rFVIIa arm presented with a thromboembolic complication, while only two patients $(6 \%)$ presented with such a complication in the placebo arm. The estimated RR for thrombotic complications in this study was 2.36 (95\% CI 0.53 to 10.51 ).

\section{Secondary outcomes}

The secondary outcomes were only reported by Narayan 2008 .

\section{Intracranial bleeding volume}

Narayan 2008 analysed the effect of rFVIIa on intracranial bleeding volume in different ways. For each arm, the investigators reported the: 1) mean volume at baseline, 24, and 72 hours; 2) mean volume change (defined as volume increase, no change, or decrease) at 24 and 72 hours; and 3) volume increase at 24 and 72 hours, only considering patients in whom an increase was reported. We reported the mean volume change at 72 hours as we considered this to be both the most relevant outcome and the most powerful analysis. The mean difference in volume change at 72 hours was $-3.10(95 \%$ CI -10.47 to 4.27$)$ for patients receiving rFVIIa in comparison to patients receiving placebo.

For the other secondary outcomes there were too few events to obtain effect estimate measures.

\section{Brain ischaemic lesions}

Narayan 2008 reported one cerebral infarction in the placebo arm and no events in the rFVIIa arm.

\section{Need for neurosurgical operation or reoperation}

Narayan 2008 reported the need for emergency intracranial bleeding evacuation for three patients in the placebo group and for one in the rFVIIa group. Two of the three placebo-treated patients who underwent the emergency evacuation needed a reoperation, while a reoperation was not conducted for the rFVIIa-treated patients who underwent the emergency evacuation.

\section{Renal failure}

Neither of the studies reported on renal failure.

\section{ISCUSSIO N}

\section{Summary of main results}

There is no reliable evidence that haemostatic drugs are effective in reducing mortality or disability in patients with TBI. Only two studies evaluating the effects of rFVIIa were found. One of them was a post-hoc analysis of a trial including 30 bleeding trauma patients with a concomitant moderate or mild TBI. This result should be considered with caution as it was a post-hoc analysis of a subgroup of patients (with TBI) within a larger trial of trauma patients. Posteriori subgroup analyses are likely to be misleading as they can be the result of data dredging and chance. The other study included 97 TBI patients with evidence of intracerebral bleeding in the initial CT scan.

Both studies were too small to confirm or refute a clinically plausible effect in the TBI population. We did not find a single randomised controlled trial of an antifibrinolytic drug for TBI patients. The pending results of the Novoseven study and the results of the ongoing studies with tranexamic acid (TXA) will provide useful information about the effects of haemostatic drugs in TBI patients.

\section{Quality of the evidence}

Neither of the trial reports provided enough data to assess the risk of bias for sequence generation, allocation concealment, blinding, or selective reporting.

\section{Potential biases in the review process}

Although our search was comprehensive and we used validated search strategies, the possibility of publication bias cannot be ruled out. Because few studies were included in this review we were not able to conduct formal analysis of publication bias (a funnel plot). Full protocols of the included studies were not available so we could not assess the presence of selective reporting bias, however for our primary outcome (mortality) this type of bias is very unlikely. Finally, one of the included trials was a post-hoc subgroup analysis and its result should be considered with caution.

\section{Agreements and disagreements with other studies or reviews}

This is the first review to evaluate the effects of haemostatic drugs in TBI patients. However, other reviews related to this question have been published.

Stanworth and collaborators conducted a systematic review on rFVIIa for the prevention and treatment of bleeding in patients without haemophilia (Stanworth 2007). This review included the randomised controlled trial in trauma patients from which the post-hoc analysis reported in our systematic review was conducted (Boffard 2005). However, that review did not analyse the effect of rFVIIa in TBI patients.

Another Cochrane review evaluated the effects of antifibrinolytic agents in trauma patients (Coats 2004). That review included two studies, one of them (Auer 1979) is among the excluded studies for our review. The trial involved TBI patients and the intervention under study was aprotinin, but the report provided no useable 
outcome data. The other study reported in the review by Coats and collaborators did not include TBI patients.

A recent review of the clinical use of rFVIIa evaluated the effects of rFVIIa in different conditions usually treated in the emergency department (Fishman 2008). Among the outcomes, the effect on trauma patients was reported although TBI patients were not specifically included. The only included randomised controlled trial involving trauma patients was by Boffard 2005, which is included in this systematic review.

\section{A U THORS' CONCLUSIONS}

\section{Implications for practice}

There is no reliable evidence to recommend the use of haemostatic drugs for TBI patients.

\section{Implications for research}

New randomised clinical trials assessing the effects of haemostatic drugs in TBI patients should be conducted. These trials should be large enough to detect clinically plausible effects.

\section{R E F E R E N C E S}

\section{References to studies included in this review}

Kluger 2007 \{published data only\}

Kluger Y, Riou B, Rossaint R, Rizoli SB, Boffard $\mathrm{KD}$, Choong PI, Warren B, et al.Safety of rFVIIa in hemodynamically unstable polytrauma patients with traumatic brain injury: post hoc analysis of 30 patients from a prospective, randomized, placebo-controlled, doubleblind clinical trial. Critical Care 2007;11(4):R85.

Narayan 2008 \{published data only\}

Narayan RK, Maas AI, Servadei F, Skolnick BE, Tillinger MN, Marshall LF. Progression of traumatic intracerebral hemorrhage: a prospective observational study. Journal of Neurotrauma 2008;25(6):629-39.

\section{References to studies excluded from this review}

Auer 1979 \{published data only\}

Auer LM, Marth E, Heppner F, Holasek A. Proteolytic enzyme activity in patients with severe head injury and the effect of a proteinase inhibitor. Acta Neurochirurgica 1979; 49(3-4):207-17.

\section{References to studies awaiting assessment}

Novoseven Study \{unpublished data only\}

\section{References to ongoing studies}

CRASH-2 Trial \{published data only\}

CRASH-2.. Ongoing study May 2005.

Tranexamic acid in TBI \{published data only\} Tranexamic Acid for Preventing Progressive Intracranial Haemorrhage in Traumatic Brain Injury.. Ongoing study October 2008

\section{Additional references}

Astrup 2006

Astrup J. "Ultra-early" antifibrinolytic treatment of subarachnoidal bleeding with tranexamic acid. Ugeskrift for Laeger 2006;168(11):1107-11.
Boffard 2005

Boffard KD, Riou B, Warren B, Choong PI, Rizoli S, Rossaint R, et al.Recombinant factor VIIa as adjunctive therapy for bleeding control in severely injured trauma patients: two parallel randomized placebo controlled double blind clinical trials. Journal of Trauma 2005;59:8-18.

Bullock 2006

Bullock MR, Chesnut R, Ghajar J, Gordon D, Hart R, Newell DW, et al.Surgical management of traumatic parenchymal lesions. Neurosurgery 2006;58 Suppl(3):2546; discussion i-iv.

Ceylan 1992

Ceylan S, Kuzeyli K, Ilbay K, Akturk F. Non operative management of acute extradural hematomas in children. Journal of Neurosurgical Science 1992;36(2):85-8.

Coats 2004

Coats T, Roberts IG, Shakur H. Antifibrinolytic drugs for acute traumatic injury. Cochrane Database of Systematic Reviews 2004, Issue 4. [DOI: 10.1002/ 14651858.CD004896.pub2]

\section{CRASH Trial}

Edwards P, Arango M, Balica L, Cottingham R, El-Sayed H, Farrell B, et al.Final results of MRC CRASH, a randomised placebo-controlled trial of intravenous corticosteroid in adults with head injury-outcomes at 6 months. Lancet 2005;365(9475):1957-9.

CRASH-2 Trial

CRASH-2 Collaborators. Improving the evidence base for trauma care: progress in the international CRASH-2 trial. PLoS Clinical Trials 2006;1(6):30.

Fishman 2008

Fishman PE, Drumheller BC, Dubon ME, Slesinger TL. Recombinant activated factor VII use in the emergency department. Emergency Medicine Journal 2008;25:625-30.

Ghajar 2000

Ghajar J. Traumatic brain injury. Lancet 2000;356(9233): 923-9. 
Henry 2007

Henry DA, Carless PA, Moxey AJ, O'Connell D, Stokes BJ, McClelland B, et al.Anti-fibrinolytic use for minimising perioperative allogeneic blood transfusion. Cochrane Database of Systematic Reviews 2007, Issue 4. Art. No.: CD001886. DOI: 10.1002/14651858.CD001886.pub2. [DOI: 10.1002/14651858.CD001886.pub2]

Holcomb 2004

Holcomb JB. Methods for improved hemorrhage control. Critical Care 2004;8 Suppl 2:57-60.

Hyder 2007

Hyder AA, Wunderlich CA, Puvanachandra P, Gururaj G, Kobusingye OC. The impact of traumatic brain injuries: a global perspective. NeuroRehabilitation 2007;22(5): $341-53$.

\section{Langlois 2006}

Langlois JA, Rutland-Brown W, Thomas KE. Traumatic brain injury in the United States: emergency department visits, hospitalizations, and deaths. Atlanta (GA): Centers for Disease Control and Prevention, National Center for Injury Prevention and Control; 2006.

Maas 2007

Maas AI, Marmarou A, Murray GD, Teasdale SG, Steyerberg EW. Prognosis and clinical trial design in traumatic brain injury: the IMPACT study. Journal of Neurotrauma 2007;24(2):232-8.

\section{Mandera 1999}

Mandera M, Zralek C, Krawczyk I, Zycinski A, Wencel T, Bazowski P. Surgery or conservative treatment in children with traumatic intracerebral haematoma. Child's Nervous System 1999;15(5):267-9; discussion 270.

Mannucci 2007

Mannucci PM, Levi M. Prevention and treatment of major blood loss. New England Journal of Medicine 2007;356(22): 2301-11.

Mayer 2008

Mayer SA, Brun NC, Begtrup K, Broderick J, Davis S, Diringer $\mathrm{MN}$, et al.Efficacy and safety of recombinant activated factor VII for acute intracerebral hemorrhage. New England Journal of Medicine 2008;358(20):2127-37.

Perel 2008

Perel P, Arango M, Clayton T, Edwards P, Komolafe E, Poccock $S$, et al.Predicting outcome after traumatic brain injury: practical prognostic models based on large cohort of international patients. BMJ 2008;336(7641):425-9.

\section{Prentice 1980}

Prentice CR. Basis of antifibrinolytic therapy. Journal of Clinical Pathology. Supplement 1980;14:35-40.

\section{Roos 2003}

Roos YB, Rinkel GJ, Vermeulen M, Algra A, Van Gijn J. Antifibrinolytic therapy for aneurysmal subarachnoid haemorrhage. Cochrane Database of Systematic Reviews 2003, Issue 2. [DOI: 10.1002/14651858.CD001245]

\section{Slaughter 1997}

Slaughter TF, Greenberg CS. Antifibrinolytic drugs and perioperative hemostasis. American Journal of Hematology 1997;56(1):32-6

\section{Stanworth 2007}

Stanworth S, Birchall J, Doree C, Hyde C. Recombinant factor VIIa for the prevention and treatment of bleeding in patients without haemophilia. Cochrane Database of Systematic Reviews 2007, Issue 2. [DOI: 10.1002/ 14651858.CD005011.pub2]

\section{Tranexamic Acid in TBI}

Surakrant Y. Tranexamic Acid for Preventing Progressive Intracranial Haemorrhage in Traumatic Brain Injury. Accessed at http://clinicaltrials.gov/ 13 July 2009.

\section{You 2006}

You H, Al-Shahi R. Haemostatic drug therapies for acute primary intracerebral haemorrhage. Cochrane Database of Systematic Reviews 2006, Issue 3. [DOI: 10.1002/ 14651858.CD005951.pub2]

* Indicates the major publication for the study 


\section{CHARACTERISTICS OF STUDIES}

\section{Characteristics of included studies [ordered by study ID]}

\section{Kluger 2007}

\begin{tabular}{|c|c|c|}
\hline Methods & \multicolumn{2}{|c|}{ Randomised clinical trial. } \\
\hline Participants & \multicolumn{2}{|c|}{$\begin{array}{l}30 \text { adult patients (between } 16 \text { and } 65 \text { years old) with severe blunt trauma and moderate } \\
\text { or mild traumatic brain injury (based on CT scan results) } \\
\text { Exclusion criteria were: cardiac arrest pre-hospital or in the emergency or operating room, } \\
\text { prior to trial drug administration; gunshot wound to the head; base deficit of greater } \\
\text { than } 15 \mathrm{mEq} / 1 \text { or severe acidosis with } \mathrm{pH} \text { of less than } 7.00 \text {; transfusion of } 8 \text { or more } \\
\text { units of RBCs prior to arrival at the trauma center; injury sustained greater than or equal } \\
\text { to } 12 \text { hours before randomisation; and severe TBI, defined as a Glasgow Coma Scale } \\
\text { (GCS) score of less than or equal to } 8 \text {, unless in the presence of a normal head CT scan }\end{array}$} \\
\hline Interventions & \multicolumn{2}{|c|}{$\begin{array}{l}\text { Eligible patients were randomly assigned to treatment groups within a 4-hour period. } \\
\text { Treatment arms were either three intravenous injections of rFVIIa }(200,100 \text {, and } 100 \mu \mathrm{g} / \\
\mathrm{kg} \text { ) or three placebo injections. The first dose of study drug was administered immediately } \\
\text { after transfusion of the eighth unit of RBCs. The second and third doses followed } 1 \text { and } \\
3 \text { hours after the first dose, respectively }\end{array}$} \\
\hline Outcomes & \multicolumn{2}{|c|}{ Mortality was categorised as: early ( $<48$ hours) or late (between 48 hours and 30 days) } \\
\hline Notes & \multicolumn{2}{|c|}{$\begin{array}{l}\text { This study was a post hoc analysis of patients with traumatic brain injury enrolled into } \\
\text { a randomised, placebo-controlled study of patients with severe blunt trauma }\end{array}$} \\
\hline \multicolumn{3}{|l|}{ Risk of bias } \\
\hline Item & Authors' judgement & Description \\
\hline Adequate sequence generation? & Unclear & Not described. \\
\hline Allocation concealment? & Unclear & Not described. \\
\hline $\begin{array}{l}\text { Blinding? } \\
\text { All outcomes }\end{array}$ & Unclear & $\begin{array}{l}\text { Reported as "double blind" but method of blinding was not } \\
\text { reported }\end{array}$ \\
\hline $\begin{array}{l}\text { Incomplete outcome data addressed? } \\
\text { All outcomes }\end{array}$ & Yes & Outcome reported for all included patients. \\
\hline Free of selective reporting? & Unclear & The protocol is not available. \\
\hline Free of other bias? & Unclear & - \\
\hline
\end{tabular}


Narayan 2008

\begin{tabular}{ll}
\hline Methods & Randomised clinical trial. \\
\hline Participants & $\begin{array}{l}97 \text { adult patients }(>18 \text { years old) with traumatic brain injury, a Glasgow Coma Scale } \\
(\mathrm{GCS}) \text { score between } 4 \text { and } 14 \text {, and evidence of traumatic intracerebral bleeding with } \\
\text { a total volume of at least } 2 \mathrm{ml} \text { on the baseline CT scan obtained within } 6 \text { hours of the } \\
\text { injury } \\
\text { Exclusion criteria were: the presence of penetrating head or spinal cord injury; life ex- } \\
\text { pectancy of less than } 24 \text { hours after hospital admission; any planned surgical evacua- } \\
\text { tion of intracerebral haematoma within } 24 \text { hours after dosing; isolated subarachnoid } \\
\text { haemorrhage, intraventricular haemorrhage, epidural or subdural haematomas or sICH; } \\
\text { significant cardiovascular disease or dysfunction; haemodynamic instability; known his- } \\
\text { tory of hypercoagulability or thromboembolism; current vitamin K antagonist use; and } \\
\text { pregnancy }\end{array}$ \\
\hline
\end{tabular}

Interventions

Five doses of rFVIIa $(40,80,120,160$, and $200 \mu \mathrm{g} / \mathrm{kg})$ were compared with placebo in escalating dose tiers. The first dose tier $(40 \mu \mathrm{g} / \mathrm{kg})$ was assigned in a $1: 1$ ratio to the treatment or placebo group. Subsequent dose tiers were assigned in a 2:1 ratio

Outcomes

The primary objective of this study was to evaluate safety of the intervention. All adverse events, defined as deep vein thrombosis (DVT), pulmonary embolism (PE), myocardial infarction, cerebral infarction, disseminated intravascular coagulation or coagulopathy were reported until day 15

Early mortality was defined as within 15 days of recruitment, and late mortality as any death after 15 days of recruitment

The effectiveness assessment focused on changes in haematoma volumes on CT scans between baseline, 24 hours, and 72 hours after the intervention

Notes

Risk of bias

\begin{tabular}{lll} 
Item & Authors' judgement & Description \\
\hline $\begin{array}{l}\text { Adequate sequence generation? } \\
\text { Allocation concealment? }\end{array}$ & Unclear & Not described. \\
\hline $\begin{array}{l}\text { Blinding? } \\
\text { All outcomes }\end{array}$ & Unclear & Not described. \\
\hline $\begin{array}{l}\text { Incomplete outcome data addressed? } \\
\text { All outcomes }\end{array}$ & Yes & $\begin{array}{l}\text { Reported as "double blind" but method of blinding was not } \\
\text { reported }\end{array}$ \\
\hline $\begin{array}{l}\text { Free of selective reporting? } \\
\text { Free of other bias? }\end{array}$ & $\begin{array}{l}\text { Outcome reported for all the patients included. The only } \\
\text { exception was late mortality (more than 15 days) for which } \\
\text { the authors stated that they did not record it systemati- } \\
\text { cally for all the patients but recorded only those in-hospital } \\
\text { deaths reported by collaborators }\end{array}$ \\
\hline
\end{tabular}

Haemostatic drugs for traumatic brain injury (Review)

Copyright $\odot 2010$ The Cochrane Collaboration. Published by John Wiley \& Sons, Ltd. 
Characteristics of excluded studies [ordered by study ID]

\begin{tabular}{ll}
\hline Study & Reason for exclusion \\
\hline Auer 1979 & $\begin{array}{l}\text { This study is described as a randomised controlled trial of aprotinin versus placebo in patients with severe traumatic } \\
\text { brain injury but, after randomly allocating the first } 20 \text { patients, five patients were added to the aprotinin group. Because } \\
\text { it was not possible to separate the outcome data for the } 20 \text { randomised and the five non-randomised patients, this study } \\
\text { provided no useable outcome data }\end{array}$ \\
\hline
\end{tabular}

Characteristics of studies awaiting assessment [ordered by study ID]

\section{Novoseven Study}

\begin{tabular}{|c|c|}
\hline Methods & Randomised controlled trial. \\
\hline Participants & 550 severely injured trauma patients with bleeding refractory to standard treatment \\
\hline Interventions & Three single doses of rFVIIa $(200 \mu \mathrm{g} / \mathrm{kg}+100 \mu \mathrm{g} / \mathrm{kg}+100 \mu \mathrm{g} / \mathrm{kg})$ or placebo \\
\hline Outcomes & Mortality at 30 days. \\
\hline Notes & $\begin{array}{l}\text { This study planned to recruit } 1502 \text { patients but after recruiting } 550 \text { patients, in June } 2008 \text { the sponsor (Novo } \\
\text { Nordisk) made the announcement that they were stopping this trial as it was futile. Some of the patients recruited } \\
\text { in this trial had traumatic brain injury and could provide useful data for this systematic review. We contacted Novo } \\
\text { Nordisk but we were unable to obtain any data }\end{array}$ \\
\hline
\end{tabular}

\section{Characteristics of ongoing studies [ordered by study ID]}

\section{CRASH-2 Trial}

\begin{tabular}{|c|c|}
\hline Trial name or title & CRASH-2. \\
\hline Methods & Randomised clinical trial. \\
\hline Participants & $\begin{array}{l}\text { Adults with trauma who are within } 8 \text { hours of injury and have either significant haemorrhage or are considered } \\
\text { to be at risk of significant haemorrhage. The trial will recruit } 20,000 \text { patients and is planned to finish in } \\
\text { December } 2009\end{array}$ \\
\hline Interventions & $2 \mathrm{~g}$ of tranexamic acid or placebo. \\
\hline Outcomes & $\begin{array}{l}\text { Primary outcome: death in hospital within four weeks of injury } \\
\text { Secondary outcome: receipt of a blood product transfusion, the number of units of blood products transfused, } \\
\text { surgical intervention, and the occurrence of thromboembolic episodes }\end{array}$ \\
\hline Starting date & May 2005 \\
\hline
\end{tabular}




\section{CRASH-2 Trial (Continued)}

Contact information CRASH@lshtm.ac.uk

Notes

Tranexamic acid in TBI

Trial name or title Tranexamic Acid for Preventing Progressive Intracranial Haemorrhage in Traumatic Brain Injury

\begin{tabular}{ll}
\hline Methods & Randomised clinical trial. \\
\hline Participants & Adult patients with moderate or severe TBI. \\
\hline Interventions & 2 g of tranexamic acid or placebo. \\
\hline Outcomes & $\begin{array}{l}\text { Primary outcome: progressive intracranial haemorrhage at } 24 \pm 8 \text { hours confirmed by repeated CT of the } \\
\text { brain } \\
\text { Secondary outcome: functional scale (GOS, DRS), mortality, operative treatment (later surgery for bleeding) } \\
\text {, adverse effect and transfusion needed }\end{array}$ \\
\hline Starting date & October 2008 \\
\hline Contact information & surakrant@gmail.com \\
\hline Notes & \\
\hline
\end{tabular}


DATA ANDANALYSES

\section{Comparison 1. Outcomes}

\begin{tabular}{|c|c|c|c|c|}
\hline Outcome or subgroup title & $\begin{array}{l}\text { No. of } \\
\text { studies }\end{array}$ & $\begin{array}{c}\text { No. of } \\
\text { participants }\end{array}$ & Statistical method & Effect size \\
\hline 1 Mortality & 2 & & Risk Ratio (M-H, Fixed, 95\% CI) & Totals not selected \\
\hline 2 Thrombotic complication & 2 & & Risk Ratio (M-H, Fixed, 95\% CI) & Totals not selected \\
\hline $\begin{array}{l}3 \text { Change in volume of intracranial } \\
\text { bleeding }\end{array}$ & 1 & & Mean Difference (IV, Fixed, 95\% CI) & Totals not selected \\
\hline
\end{tabular}

Analysis I.I. Comparison I Outcomes, Outcome I Mortality.

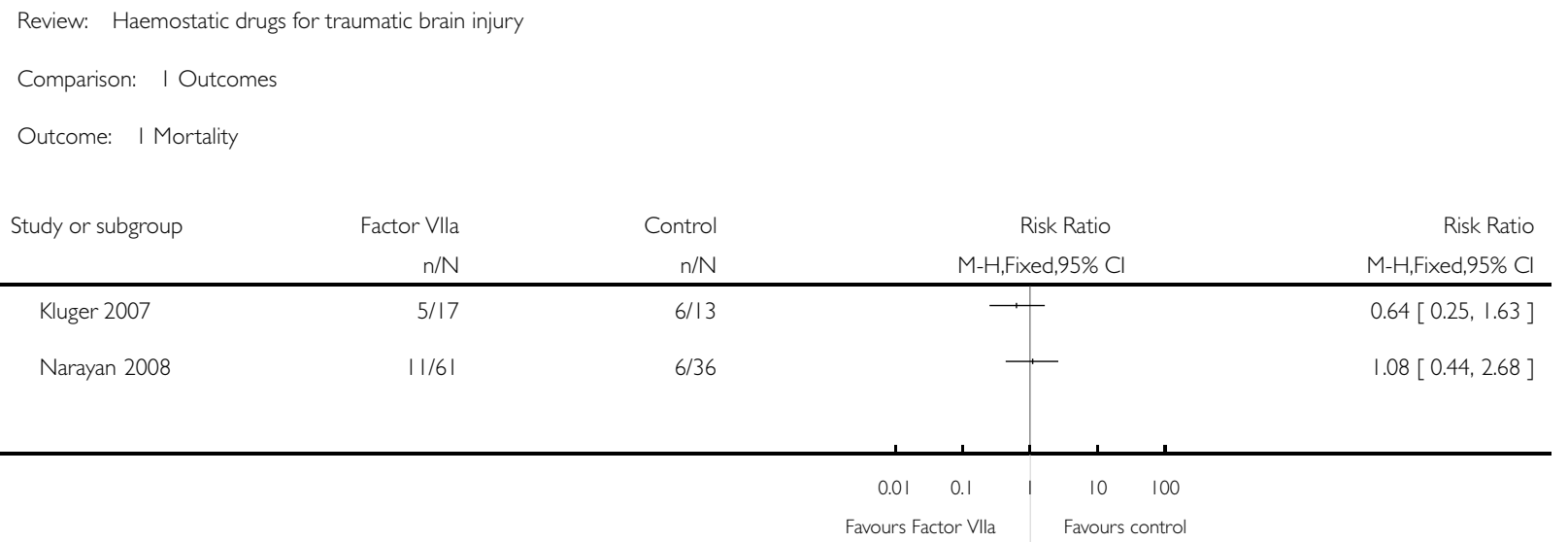




\section{Analysis I.2. Comparison I Outcomes, Outcome 2 Thrombotic complication.}

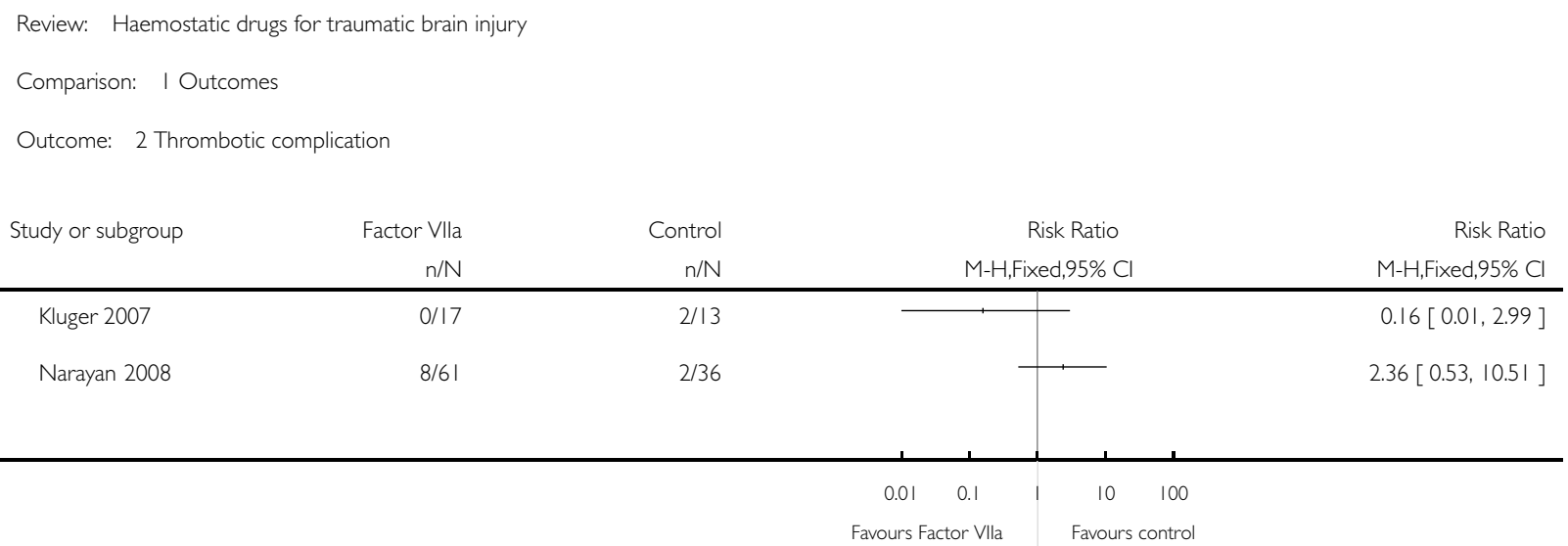

\section{Analysis I.3. Comparison I Outcomes, Outcome 3 Change in volume of intracranial bleeding.}

Review: Haemostatic drugs for traumatic brain injury

Comparison: I Outcomes

Outcome: 3 Change in volume of intracranial bleeding

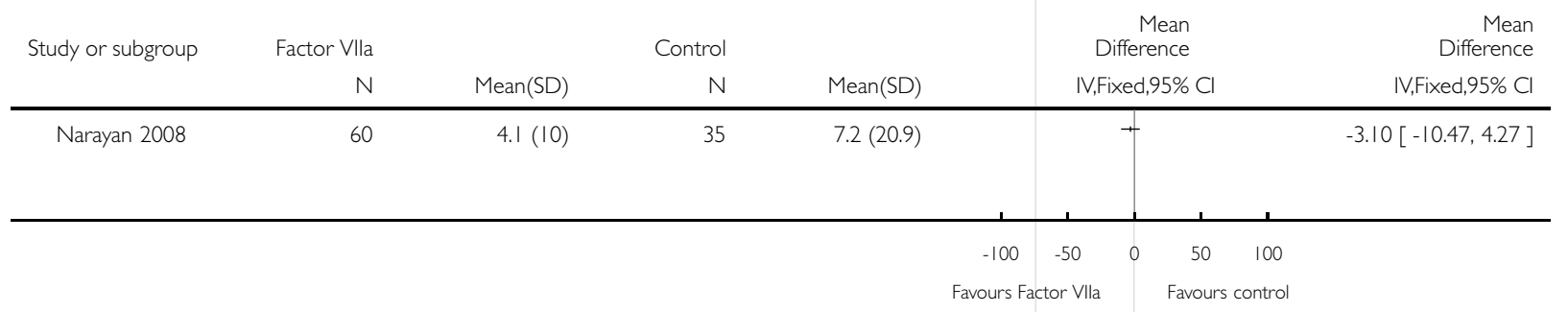




\section{A P P E N D I C E S}

\section{Appendix I. Search strategy}

Cochrane Injuries Group Specialised Register (searched 3 February 2009)

1. ((haemosta* or hemosta* or antihaemorrhag* or antihemorrhag*) and (drug* or agent* ${ }^{*}$ or treat* or therap $\left.{ }^{*}\right)$ ) or $\left(\left(\right.\right.$ coagulat $^{*}$ or $^{*}$ clotting) and (factor*)) or ("Tranexamic Acid" or Antithrombins* or anti-fibrinolytic* or antifibrinolytic* or antifibrinolysin* or antifibrinolysin* or antiplasmin* or anti-plasmin* or "plasmin inhibitors" or "thrombin inhibitors" or "factor 7a" or "factor VIIa" or factor IXa)

2. ((head or crani* ${ }^{*}$ or cerebr* or capitis or brain* or forebrain* or skull* or hemispher* or intra-cran* or inter-cran*) and (injur* or trauma* or damag* or wound* or fracture* or contusion*)) or ((head or crani* or cerebr* or brain* or intra-cran* or inter-cran*) and (haematoma* or hematoma* or haemorrhag* or hemorrhag* or bleed* or pressure)) or ((brain or cerebral or intracranial) and (oedema or edema or swell*)) or ((unconscious* or coma* or concuss* or 'persistent vegetative state') and (injur* or trauma* or damag* or wound* or fracture*)) or ("Glasgow coma score") or ("Glasgow outcome score") or ("Glasgow coma scale") or ("Glasgow outcome scale") or ("diffuse axonal injury" or "diffuse axonal injuries")

3. 1 and 2

\section{CENTRAL (The Cochrane Library 2009, Issue 1)}

\#1 MeSH descriptor Craniocerebral Trauma explode all trees

\#2 MeSH descriptor Cerebrovascular Trauma explode all trees

\#3 MeSH descriptor Brain Edema explode all trees

\#4 (brain or cerebral or intracranial) next (oedema or edema or swell*)

\#5 MeSH descriptor Glasgow Coma Scale explode all trees

\#6 MeSH descriptor Glasgow Outcome Scale explode all trees

\#7 MeSH descriptor Unconsciousness explode all trees

\#8 glasgow next (coma or outcome) next (score or scale)

\#9 (Unconscious* or coma* or concuss* or 'persistent vegetative state') near5 (injur* or trauma* or damag* or wound* or fracture*)

\#10 "Rancho Los Amigos Scale"

\#11 (head or crani* or cerebr* or capitis or brain* or forebrain* or skull* or hemispher* or intra-cran* or inter-cran*) near3 (injur* or trauma* or damag* or wound* or fracture* or contusion*)

\#12 Diffuse next axonal next injur*

\#13 (head or crani* or cerebr* or brain* or intra-cran* or inter-cran*) near3 (haematoma* or hematoma* or haemorrhag* or hemorrhag* or bleed* or pressure)

\#14 (\#1 OR \#2 OR \#3 OR \#4 OR \#5 OR \#6 OR \#7 OR \#8 OR \#9 OR \#10 OR \#11 OR \#12 OR \#13)

$\# 15 \mathrm{MeSH}$ descriptor Hemostatics explode all trees

\#16 MeSH descriptor Blood Coagulation Factors explode all trees

\#17 MeSH descriptor Hemostasis explode all trees with qualifier: DE

\#18 MeSH descriptor Blood Coagulation explode all trees with qualifier: DE

\#19 MeSH descriptor Fibrinolysis explode all trees with qualifier: DE

\#20 MeSH descriptor Platelet Activation explode all trees with qualifier: DE

\#21 MeSH descriptor Antithrombins explode all trees with qualifier: DE

\#22 MeSH descriptor Thrombin explode all trees with qualifier: DE

\#23 (haemosta* $^{*}$ or hemosta* ${ }^{*}$ or antihaemorrhag* or antihemorrhag*) near5 (drug* or agent* or treat* or therap*):ab,ti

\#24 (coagulat* or clotting) next (factor*):ab,ti

\#25 MeSH descriptor Factor VIIa explode all trees

\#26 (factor) next (7a or VIIa or VII):ab,ti

\#27 MeSH descriptor Factor IXa explode all trees

\#28 MeSH descriptor Estrogens, Conjugated (USP) explode all trees

\#29 (conjugated next estrogen*) or (carentil or congest or dagynil or oestrofeminal or estro-feminal or oestro-feminal or prelestrin or premarin or climarest or climopax or presomen or progens or transannon or femavit):ab,ti

\#30 MeSH descriptor Erythropoietin explode all trees

\#31 MeSH descriptor Erythropoietin, Recombinant explode all trees

\#32 erythropoietin or recormon or epoetin alfa or epogen or eprex:ti,ab

\#33 MeSH descriptor Deamino Arginine Vasopressin explode all trees

Haemostatic drugs for traumatic brain injury (Review)

Copyright $\odot 2010$ The Cochrane Collaboration. Published by John Wiley \& Sons, Ltd. 
\#34 (deamino next arginine) or (desmopressin or adiuretin or apo-desmopressin or ddavp or desmopressine or desmospray or desmotabs or octim or octostim or minirin or minurin or desmogalen or nocutil or stimate or Arginine or Vasopressins or DDVAP):ti

\#35 MeSH descriptor Antifibrinolytic Agents explode all trees

\#36 MeSH descriptor Aprotinin explode all trees

\#37 MeSH descriptor Aminocaproic Acids explode all trees

\#38 MeSH descriptor Tranexamic Acid explode all trees

\#39 (aminocaproic or 6-aminohexanoic or epsilon-aminocaproic) next (acid*):ti

\#40 (tranexamic acid or TXA or amcha or amca or cyklokapron or kabi-2161 or transamin or ugurol or t-amcha or trans-4-aminomethylcyclohexanecarboxylic acid or EACA):ab,ti

\#41 (amicar or caprocid or epsamon or epsikapron or aprotinin* or BPTI or antilysin or contrical or contrykal or dilmintal or iniprol or kontrikal or kontrykal or pulmin or trasylol or zymofren or argatroban):ab,ti

\#42 (Basic or bovine or kunitz or kallikrein) next (trypsin inhibitor* or trypsin inactivator*):ab,ti

\#43 (kallikrein-trypsin or bovine pancreatic trypsin or tranexamic or cyklokapron or pharmacia or $\mathrm{t}$-amcha or amcha or ugurol or transamin or kabi or epsilon-aminocaproic acid or aminocaproic or lederle):ab,ti

\#44 (anti-fibrinolytic* or antifibrinolytic* or antifibrinolysin* or anti-fibrinolysin* or antiplasmin* or anti-plasmin*) or (plasmin next inhibitor*) or (thrombin next inhibitor*):ab,ti

\#45 (\#15 OR \#16 OR \#17 OR \#18 OR\#19 OR \#20 OR \#21 OR \#22 OR \#23 OR \#24 OR \#25 OR \#26 OR \#27 OR \#28 OR \#29

OR \#30 OR \#31 OR\#32 OR \#33 OR \#34 OR \#35 OR \#36 OR \#37 OR \#38 OR \#39 OR \#40 OR \#41 OR \#42 OR \#43 OR \#44)

\#46 (\#14 AND \#45)

MEDLINE (Ovid SP) 1950 to week 3 January 2009

1. exp Craniocerebral Trauma/

2. exp Brain Edema/

3. exp Glasgow Coma Scale/

4. exp Glasgow Outcome Scale/

5. exp Unconsciousness/

6. exp Cerebrovascular Trauma/

7. ((head or crani* ${ }^{*}$ or cerebr* or capitis or brain* or forebrain* or skull* or hemispher* or intra-cran* or inter-cran*) adj3 (injur* or trauma* or damag* or wound* or fracture* or contusion*)).ab,ti.

8. ((head or crani* or cerebr* or brain* or intra-cran* or inter-cran*) adj3 (haematoma* or hematoma* or haemorrhag* or hemorrhag* or bleed* or pressure)).ti,ab.

9. (Glasgow adj (coma or outcome) adj (scale* or score*)).ab,ti.

10. "rancho los amigos scale".ti,ab.

11. ("diffuse axonal injury" or "diffuse axonal injuries").ti,ab.

12. ((brain or cerebral or intracranial) adj (oedema or edema or swell*)).ab,ti.

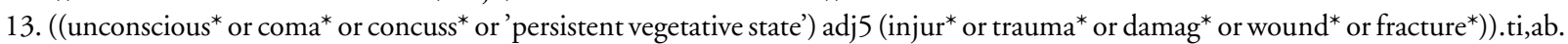

14. 1 or 2 or 3 or 4 or 5 or 6 or 7 or 8 or 9 or 10 or 11 or 12 or 13

15. exp hemostatics/

16. exp blood coagulation factors/

17. hemostasis/de or blood coagulation/de or fibrinolysis/de or exp platelet activation/de or exp antithrombins/ or thrombin/ai

18. ((h?emosta* or antih?emorrhag*) adj5 (drug* or agent* or treat* or therap*)).ab,ti.

19. ((coagulat* or clotting) adj factor*).ab,ti.

20. exp Factor VIIa/

21. (factor adj (7a or VIIa or VII)).ab,ti.

22. exp factor ixa/

23. exp "Estrogens, Conjugated (USP)"/

24. ((conjugated adj3 estrogen*) or carentil or congest or dagynil or oestrofeminal or estro-feminal or oestro-feminal or prelestrin or premarin or climarest or climopax or presomen or progens or transannon or femavit).ab,ti.

25. exp Erythropoietin/ or exp Erythropoietin, Recombinant/ or exp Receptors, Erythropoietin/

26. (erythropoietin or recormon or epoetin alfa or epogen or eprex).ti,ab.

27. exp Deamino Arginine Vasopressin/

28. ((deamino adj arginine) or desmopressin or adiuretin or apo-desmopressin or ddavp or desmopressine or desmospray or desmotabs or octim or octostim or minirin or minurin or desmogalen or nocutil or stimate or Arginine or Vasopressins or DDVAP).ti.

29. exp Antifibrinolytic Agents/

Haemostatic drugs for traumatic brain injury (Review)

Copyright @ 2010 The Cochrane Collaboration. Published by John Wiley \& Sons, Ltd. 
30. exp Aprotinin/

31. exp Aminocaproic Acids/

32. exp Tranexamic Acid/

33. ((aminocaproic or 6-aminohexanoic or epsilon-aminocaproic) adj acid*).ti,ab.

34. (tranexamic acid or TXA or amcha or amca or cyklokapron or kabi-2161 or transamin or ugurol or t-amcha or trans-4-aminomethylcyclohexanecarboxylic acid or EACA).ab,ti.

35. (amicar or caprocid or epsamon or epsikapron or aprotinin* or BPTI or antilysin or contrical or contrykal or dilmintal or iniprol or kontrikal or kontrykal or pulmin or trasylol or zymofren or argatroban).ab,ti.

36. ((Basic or bovine or kunitz or kallikrein) adj (trypsin inhibitor* or trypsin inactivator*)).ab,ti.

37. (kallikrein-trypsin or bovine pancreatic trypsin or tranexamic or cyklokapron or pharmacia or t-amcha or amcha or ugurol or transamin or kabi or epsilon-aminocaproic acid or aminocaproic or lederle).ab,ti.

38. (anti-fibrinolytic* or antifibrinolytic* or antifibrinolysin* or anti-fibrinolysin* or antiplasmin* or anti-plasmin* or (plasmin adj inhibitor*) or (thrombin adj inhibitor*)).ab,ti.

39.15 or 16 or 17 or 18 or 20 or 21 or 22 or 23 or 24 or 25 or 26 or 27 or 28 or 29 or 30 or 31 or 32 or 33 or 34 or 35 or 36 or 37 or 38

40. 14 and 39

41. randomi?ed.ab,ti.

42. randomized controlled trial.pt.

43. controlled clinical trial.pt.

44. placebo.ab.

45. clinical trials as topic.sh.

46. randomly.ab.

47. trial.ti.

48. 41 or 42 or 43 or 44 or 45 or 46 or 47

49. (animals not (humans and animals)).sh.

50. 48 not 49

51.40 and 50

PubMed (www.ncbi.nlm.nih.gov/sites/entrez/) (searched 3 Feb 2009: added to PubMed in the last 180 days)

\#1 ((haemosta* or hemosta* or antihaemorrhag* or antihemorrhag*) and (drug or drugs or agent* or treatment* or therapy or therapies or therapeutic $)$ ) or ((coagulat* or clotting) and (factor or factors)) or ("Tranexamic Acid" or Antithrombins* or anti-fibrinolytic* or antifibrinolytic* or antifibrinolysin* or anti-fibrinolysin* or antiplasmin* or anti-plasmin* or "plasmin inhibitors" or "thrombin inhibitors" or "factor 7a" or "factor VIIa" or factor IXa)

\#2((head or craniu* or crania* or cerebra* or cerebru* or capitis or brain* or forebrain* or skull* or hemispher* or intra-cran* ${ }^{*}$ or inter-cran*) and (injury or injuries or trauma or traumas or traumatic or damag* or wound* or fracture* or contusion*)) or $(($ head or craniu* or crania* $^{*}$ or cerebra* or cerebru* or brain* or intra-cran* or inter-cran*) and (haematoma* or hematoma* or haemorrhag* ${ }^{*}$ hemorrhag* or bleed* $^{*}$ or pressure) $)$ or ((brain or cerebral or intracranial) and (oedema or edema or swell*)) or ((unconscious* or coma* or concuss* or 'persistent vegetative state') and (injury or injuries or trauma or traumas or traumatic or damag* or wound* or fracture*)) or ("Glasgow coma score") or ("Glasgow outcome score") or ("Glasgow coma scale") or ("Glasgow outcome scale") or ("diffuse axonal injury" or "diffuse axonal injuries")

\#3((randomized controlled trial[pt] OR controlled clinical trial[pt]) OR (randomized OR randomised OR randomly OR placebo[tiab]) OR (trial[ti]) OR (“Clinical Trials as Topic”[MeSH Major Topic])) NOT ((“Animals”[Mesh]) NOT ("Humans”[Mesh] AND "Animals"[Mesh]))

$\# 4 \# 1$ and \#2 and \#3

EMBASE (Ovid SP) 1980 to week 4 January 2009

1.exp Brain Injury/

2.exp Brain Edema/

3.exp Glasgow Coma Scale/

4.exp Glasgow Outcome Scale/

5.exp Rancho Los Amigos Scale/

6.exp Unconsciousness/

7.((brain or cerebral or intracranial) adj5 (oedema or edema or swell\$)).ab,ti.

Haemostatic drugs for traumatic brain injury (Review)

Copyright @ 2010 The Cochrane Collaboration. Published by John Wiley \& Sons, Ltd. 
8.( (head or crani $\$$ or cerebr $\$$ or capitis or brain $\$$ or forebrain $\$$ or skull\$ or hemispher $\$$ or intra-cran $\$$ or inter-cran $\$)$ adj 5 (injur $\$$ or trauma $\$$ or damag $\$$ or wound $\$$ or fracture $\$$ or contusion $\$)$ ). $a b, t i$.

9.(Glasgow adj (coma or outcome) adj (scale\$ or score\$)).ab,ti.

10.Rancho Los Amigos Scale.ab,ti.

11.((unconscious $\$$ or coma $\$$ or concuss $\$$ or 'persistent vegetative state') adj3 (injur $\$$ or trauma $\$$ or damag $\$$ or wound $\$$ or fracture\$)).ti,ab.

12.Diffuse axonal injur\$.ab,ti.

13. ( (head or crani $\$$ or cerebr $\$$ or brain $\$$ or intra-cran $\$$ or inter-cran $\$$ ) adj3 (haematoma $\$$ or hematoma $\$$ or haemorrhag $\$$ or hemorrhag $\$$ or bleed $\$$ or pressure) $)$.ab,ti.

14.or/1-13

15.exp Randomized Controlled Trial/

16.exp controlled clinical trial/

17.randomi?ed.ab,ti.

18.placebo.ab.

19. *Clinical Trial/

20.randomly.ab.

21.trial.ti.

22.15 or 16 or 17 or 18 or 19 or 20 or 21

23.exp animal/ not (exp human/ and exp animal/)

24.22 not 23

25.14 and 24

26.exp Hemostatic Agent/

27.exp Blood Clotting Factor/

28.hemostasis/de or blood coagulation/de or fibrinolysis/de or exp platelet activation/de or exp antithrombins/or thrombin/ai

29.((h?emosta* or antih?emorrhag*) adj5 (drug* or agent* or treat* or therap*)).ab,ti.

30.((coagulat* or clotting) adj factor $\left.{ }^{*}\right)$.ab,ti.

31.exp Blood Clotting Factor $7 \mathrm{a} /$

32.(factor adj (7a or VIIa or VII)).ab,ti.

33.exp Blood Clotting Factor 9a/

34.exp "Estrogens, Conjugated (USP)"/

35.((conjugated adj3 estrogen*) or carentil or congest or dagynil or oestrofeminal or estro-feminal or oestro-feminal or prelestrin or premarin or climarest or climopax or presomen or progens or transannon or femavit).ab,ti.

36.exp Erythropoietin/ or exp Recombinant Erythropoietin/ or exp Erythropoietin Receptor/

37.(erythropoietin or recormon or epoetin alfa or epogen or eprex).ti,ab.

38.exp "Argipressin[1 Deamino]"/

39.((deamino adj arginine) or desmopressin or adiuretin or apo-desmopressin or ddavp or desmopressine or desmospray or desmotabs or octim or octostim or minirin or minurin or desmogalen or nocutil or stimate or Arginine or Vasopressins or DDVAP).ti.

40.exp Antifibrinolytic Agent/

41.exp Aprotinin/

42.exp Aminocaproic Acid/ or exp Aminocaproic Acid Derivative/

43.exp Tranexamic Acid/

44.((aminocaproic or 6-aminohexanoic or epsilon-aminocaproic) adj acid*).ti,ab.

45.(tranexamic acid or TXA or amcha or amca or cyklokapron or kabi-2161 or transamin or ugurol or t-amcha or trans-4-aminomethylcyclohexanecarboxylic acid or EACA).ab,ti.

46. (amicar or caprocid or epsamon or epsikapron or aprotinin* or BPTI or antilysin or contrical or contrykal or dilmintal or iniprol or kontrikal or kontrykal or pulmin or trasylol or zymofren or argatroban).ab,ti.

47.((Basic or bovine or kunitz or kallikrein) adj (trypsin inhibitor* or trypsin inactivator*)).ab,ti.

48. (kallikrein-trypsin or bovine pancreatic trypsin or tranexamic or cyklokapron or pharmacia or $\mathrm{t}$-amcha or amcha or ugurol or transamin or kabi or epsilon-aminocaproic acid or aminocaproic or lederle).ab,ti.

49.(anti-fibrinolytic* or antifibrinolytic* or antifibrinolysin* or anti-fibrinolysin* or antiplasmin* or anti-plasmin* or (plasmin adj inhibitor*) or (thrombin adj inhibitor*)).ab,ti.

50.or/26-49

51.25 and 50

Haemostatic drugs for traumatic brain injury (Review)

Copyright $\odot 2010$ The Cochrane Collaboration. Published by John Wiley \& Sons, Ltd. 
CINAHL (EBSCO) 1982 to January 2009

$1 . S 35$ (S24 and S34)

$2 . S 34$ (S25 or S26 or S27 or S28 or S29 or S30 or S31 or S32 or S33)

$3 . S 33$ TI ( anti-fibrinolytic* or antifibrinolytic* or antifibrinolysin* or

4.anti-fibrinolysin* or antiplasmin* or anti-plasmin* ${ }^{*}$ ) or TI plasmin

5.inhibitor* or TI thrombin inhibitor*

6.S32 AB ( anti-fibrinolytic* or antifibrinolytic* or antifibrinolysin* or

7.anti-fibrinolysin* or antiplasmin* or anti-plasmin* ) or $\mathrm{AB}$ plasmin

8.inhibitor* or $\mathrm{AB}$ thrombin inhibitor*

9.S31 AB ( coagulat* or clotting) and $\mathrm{AB}$ factor*

10.S30 TI ( coagulat* or clotting) and TI factor*

11.S29 TI ( haemosta* or hemosta* $^{*}$ or antihaemorrhag* or antihemorrhag*) and

12.TI ( drug* or agent* or treat* or therap* )

13.S28 AB ( haemosta* or hemosta* or antihaemorrhag* or antihemorrhag*) and

14.AB ( drug* or agent* or treat* or therap*)

15.S27 (MH "Blood Coagulation+")

16.S26 (MH "Blood Coagulation Factors+")

17.S25 (MH "Hemostatics+") or (MH "Hemostatic Techniques+")

18.S24 (S11 and S23)

$19 . S 23$ (S12 or $S 13$ or $S 14$ or $S 15$ or $S 16$ or $S 17$ or $S 18$ or $S 19$ or $S 20$ or S21 or 20.S22)

21.S22 AB singl* W3 blind* or AB doubl* W3 blind* or AB trebl* W3 blind* or 22.AB tripl* W3 blind*

23.S21 TI singl* W3 blind* or TI doubl* W3 blind* or TI trebl* W3 blind* or

24.TI tripl* W3 blind*

25.S20 MH quantitative studies

26.S19 TX random* N3 allocat*

27.S18 MH random assignment

28.S17 TX placebo*

29.S16 MH placebos

30.S15 TX randomi?ed N3 control* N3 trial*

31.S14 TX clinical N3 trial $^{*}$

32.S13 PT clinical trial*

33.S12 MH clinical trials

$34 . S 11 S 1$ or $\mathrm{S} 2$ or $\mathrm{S} 3$ or $\mathrm{S} 4$ or $\mathrm{S} 5$ or $\mathrm{S} 6$ or $\mathrm{S} 7$ or $\mathrm{S} 8$ or $\mathrm{S} 9$ or $\mathrm{S} 10$

35.S10 TI ( head or crani* or cerebr* or brain* or intra-cran* or inter-cran*

36.) and $\mathrm{AB}$ ( haematoma* or hematoma* or haemorrhag* or hemorrhag* or bleed*

37.or pressure )

38.S9 AB ( head or crani* or cerebr* or capitis or brain* or forebrain* or

39.skull* or hemispher* or intra-cran* or inter-cran*) and TI ( injur* or

40.trauma* or damag* or wound* or fracture* or contusion*)

41.S8 TX Diffuse W1 axonal N3 injur*

42.S7 TX Rancho Los Amigos Scale

43.S6 AB ( Unconscious* or coma* or concuss* or "persistent vegetative state"

44.) and TI (injur* or trauma* or damag* or wound* or fracture*)

45.S5 TX glasgow and TX ( coma or outcome ) and TX ( score or scale )

46.S4 (MH "Unconsciousness+") or (MH "Brain Concussion+")

47.S3 (MH "Glasgow Coma Scale")

48.S2 (MH "Brain Injuries+”)

49.S1 (MH "Head Injuriest")

ISI Web of Science: Science Citation Index Expanded (SCI-EXPANDED) (1970 to January 2009) and Conference Proceedings Citation Index- Science (CPCI-S) (1990 to January 2009)

Haemostatic drugs for traumatic brain injury (Review)

Copyright $\odot 2010$ The Cochrane Collaboration. Published by John Wiley \& Sons, Ltd. 
1. Topic $=\left(\left(\right.\right.$ haemosta* $^{*}$ or hemosta* or antihaemorrhag* or antihemorrhag*) SAME $\left(\right.$ drug* $^{*}$ or agent* or treat* or therap* $\left.)\right)$ OR Topic= ((coagulat* or clotting) SAME $\left(\right.$ factor $\left.\left.^{*}\right)\right)$ OR Topic $=(($ factor $)$ SAME (7a or VIIa or VII OR IX) $)$ OR Topic $=(($ conjugated $)$ SAME (estrogen* OR oestrogen*))

2.Topic $=$ (carentil or congest or dagynil or oestrofeminal or estro-feminal or oestro-feminal or prelestrin or premarin or climarest or climopax or presomen or progens or transannon or femavit) OR Topic=(erythropoietin or recormon or epoetin alfa or epogen or eprex) AND Topic $=($ desmopressin or adiuretin or apo-desmopressin or ddavp or desmopressine or desmospray or desmotabs or octim or octostim or minirin or minurin or desmogalen or nocutil or stimate or Arginine or Vasopressins or DDVAP) AND Topic=(deamino SAME arginine)

3. Topic $=($ amicar or caprocid or epsamon or epsikapron or aprotinin* or BPTI or antilysin or contrical or contrykal or dilmintal or iniprol or kontrikal or kontrykal or pulmin or trasylol or zymofren or argatroban OR Aminocaproic Acid* OR Tranexamic Acid*) OR Topic $=($ anti-fibrinolytic* or antifibrinolytic* or antifibrinolysin* or anti-fibrinolysin* or antiplasmin* or anti-plasmin*) OR Topic= (plasmin SAME inhibitor*) OR Topic=(thrombin SAME inhibitor*)

4. Topic $=($ kallikrein-trypsin or bovine pancreatic trypsin or tranexamic or cyklokapron or pharmacia or $\mathrm{t}$-amcha or amcha or ugurol or transamin or kabi or epsilon-aminocaproic acid or aminocaproic or lederle) OR Topic=((Basic or bovine or kunitz or kallikrein) SAME (trypsin inhibitor* or trypsin inactivator*))

5.1 or 2 or 3 or 4

6. Topic $=($ glasgow SAME $($ coma or outcome $)$ SAME (score or scale $))$ OR Topic $=(($ Unconscious* or coma* or concuss* or 'persistent vegetative state') SAME (injur* or trauma* or damag* or wound* or fracture*)) OR Topic=("Rancho Los Amigos Scale" OR diffuse axonal injur*) OR Topic $=\left(\left(\right.\right.$ head or crani* ${ }^{*}$ or cerebr* or capitis or brain* or forebrain* or skull* or hemispher* or intra-cran* or intercran $^{*}$ ) same (injur* or trauma* or damag* or wound* or fracture* or contusion*)) OR Topic=((head or crani* or cerebr* or brain* or intra-cran* or inter-cran*) SAME (haematoma* or hematoma* or haemorrhag* or hemorrhag* or bleed* or pressure))

7.TS=((injur* or trauma* or lesion* or damage* or wound* or oedema* or edema* or fracture* or contusion* or concus* or commotion* or pressur*) SAME (head or crani* or capitis or brain* or forebrain* or skull* or hemisphere or intracran* or orbit*) ${ }^{*}$ OR TS= (Craniocerebral Trauma OR Cerebrovascular Trauma OR Brain Edema) OR TS=((brain or cerebral or intracranial) SAME (oedema or edema or swell $\left.{ }^{*}\right)$ )

8.6 or 7

9. Topic $=\left(\left(\right.\right.$ singl* OR doubl* OR trebl* OR tripl*) SAME $\left(\right.$ blind $^{*}$ OR mask $\left.\left.{ }^{*}\right)\right)$

10. Topic $=($ randomised OR randomized OR randomly OR random order OR random sequence OR random allocation OR randomly allocated OR at random OR randomized controlled trial) OR Topic=(controlled clinical trial OR controlled trial OR clinical trial OR placebo)

11. 9 or 10

12. 5 and 8 and 11

\section{H I S T O R Y}

Protocol first published: Issue 3, 2009

Review first published: Issue 1, 2010

\section{CONTRIBUTIONS OF AUTHORS}

PP and IR developed the search strategy, scanned the search results, extracted the data and drafted the first version of the review. SY drafted the first version of the protocol, which provides the foundation of the review.

All the authors edited and approved the review.

Haemostatic drugs for traumatic brain injury (Review) 


\section{DECLARATIONSOF INTEREST}

None known.

\section{SOURCES OF SUPPORT}

\section{Internal sources}

- Thai Cochrane Network, Thailand.

- Faculty of Medicine, Khon Kaen University, Thailand.

- Khon Kaen Hospital, Ministry of Public Health, Thailand.

- Cochrane Injuries Group, UK.

- London School of Hygiene \& Tropical Medicine, UK.

\section{External sources}

- The Thailand Research Fund, Senior Research Scholar, Thailand.

\section{DIFFERENCES BETWEEN PROTOCOLANDREVIEW}

We removed desmopressin, oestrogens, and activated factor IX from the interventions, and we focused on the most commonly used haemostatic drugs (antifibrinolytics, and rFVIIa).

\section{NDEX TERMS}

\section{Medical Subject Headings (MeSH)}

Cerebral Hemorrhage, Traumatic [ ${ }^{*}$ drug therapy]; Factor VIIa [* therapeutic use]; Head Injuries, Closed [* ${ }^{*}$ complications]; Hemostatics [*therapeutic use]; Randomized Controlled Trials as Topic; Recombinant Proteins [therapeutic use]

\section{MeSH check words}

Humans 